\title{
Annex
}

Miran Kakaee ${ }^{1}$

\section{INTRODUCTION TO THE TABLES}

The tables in the annex is based on course plans, manuals, schedules, literature lists as well as education plans collected autumn 2018 from websites, or when necessary, via direct contacts with the administration offices of the legal educations in the Nordic countries. The table and the other material about the legal educations were compiled as research material for the articles in this special issue, as well as to inform the ongoing efforts at the Law Department at Gothenburg University to reform its legal education.

The tables illustrates the course compositions of the 17 Nordic LL.M programmes. Each table is divided in seven different legal disciplines. In addition, there are four course groups; Language Studies, Other Courses, Selectable Courses, and Essays. Each legal discipline or course group include different courses e.g. Environmental Law (7 ECTS) or Labor Law (5 ECTS). The list below provides a comprehensive overview of what courses is included under each legal discipline or course group. This introduction to the tables will explain some of the choices made when compiling the annex.

The Nordic legal educations are at first glance quite similar. However, when needing to include all of the courses of the legal educations into a table that provides an easy overview, differences in detail quickly emerge, and it was not self-evident how to categorize the different courses. After pondering different options, the choice was made to depart from the seven legal disciplines used at the Department of Law at the University of Gothenburg. The reasons for this choice was mainly practical: most of the articles in this special issue relate in one way or the other to the legal education in Gothenburg. It also made sense for us to start our

\footnotetext{
${ }^{1}$ Email: miran.kakaee@fridhadvokatbyra.se
} 
categorization from what we are familiar with and know. Initially then, the seven legal disciplines Jurisprudence, Procedural Law, Criminal Law, Financial Law, Civil Law, Public Law and International Law were chosen. However, quickly it became clear that some of the courses offered by the different universities did not fit in any of the seven legal disciplines. Therefore, Language Studies, which were particularly common in Finland, received its own course group, while other courses, such as Legal Informatics, were sorted into Other Courses. A separate course group was created for Selectable Courses, which was not restricted to courses in law. A course group was also created for Essays, which consists of different thesis courses as part of receiving a bachelor's or master's degree. Additionally, certain courses consisted of more than one legal discipline. In such cases, the total amount of ECTS were multiplied with specific quotas that could be calculated by studying the course schedules and comparing the total hours attributed to each legal discipline.

During the process of compiling the course compositions of the various LL.M programmes, it became apparent that the way the law programme in Gothenburg has chosen to slot specific legal subjects into specific legal disciplines is by no means the only way to do it. Several legal subjects could easily fit within other legal disciplines. A few examples. Tax Law is in Gothenburg included in Financial Law, but at other law schools it is included in Public Law. International Private Law is in Gothenburg taught as part of Procedural Law, but it is of course also an integral part of International Law. Criminal Procedure law is in Gothenburg taught together with Procedural Law in general, but it could just as easily be included in Criminal Law. The list below after the tables provide a comprehensive overview of what legal subjects are included under what legal disciplines.

Two general observations were made when the annex was compiled that are of particular importance of the articles in this special issue. Civil Law has a dominant position across all the legal programmes, while the relevance of Jurisprudence varies both between the different Nordic countries and within each country.

Civil Law is the legal discipline including the most ECTS points in every country and LL.M programme. In Finland, Civil Law is less common when compared with other Nordic countries. On average Civil Law is teached in a scope of 46,2 ECTS, corresponding to $15,4 \%$ of the entire Finnish LL.M 
programmes, which could be compared to the LL.M programmes in Sweden, where the average amount of Civil Law equals approximately 66,9 ECTS, corresponding to almost $25 \%$ of the Swedish LL.M programmes.

In relation to courses in Jurisprudence, the Norwegian programmes offer the highest amount of ECTS - 49,3 points on average which corresponds to $16,4 \%$ of the entire programme. One needs to bear in mind, however, that the Norwegian numbers include different examen facultatum and examen philosophicum courses. In Iceland, only 17,5 ECTS (or 5,8 \%) in Jurisprudence is included in the LL.M programme. As for the Swedish programmes, the amount of ECTS in Jurisprudence varies between 15 ECTS (Gothenburg) and 29,5 ECTS (Örebro). The average Swedish amount of ECTS in Jurisprudence amounts to 23,6 ECTS which corresponds to 8,7\% of the Swedish LL.M programmes. The average LL.M programmes in Denmark and Finland offer 19,1 (6,4 \%) and 26 ECTS (8,7 \%) in Jurisprudence, respectively.

Regarding the Finnish LL.M programmes in particular, the tables show that they are the only programs where Language Studies are included (Helsinki and Rovaniemi). In addition, courses that do not fit in either of the seven legal disciplines are most common in Finland - 55 ECTS in total compared to only 9,75 ECTS in Sweden. As for Norway, the LL.M programmes offer the highest average amount of ECTS in Civil Law and Public Law when compared to other Nordic countries, 85,7 and 43 ECTS, respectively. However, Norwegian LL.M programmes offer no courses in Financial Law. In relation to the Danish LL.M programmes, they offer a high amount of ECTS in Selectable Courses. 79,2 ECTS on average. In Iceland, however, the Selectable Courses amount to 90 ECTS. 


\section{TABLES}

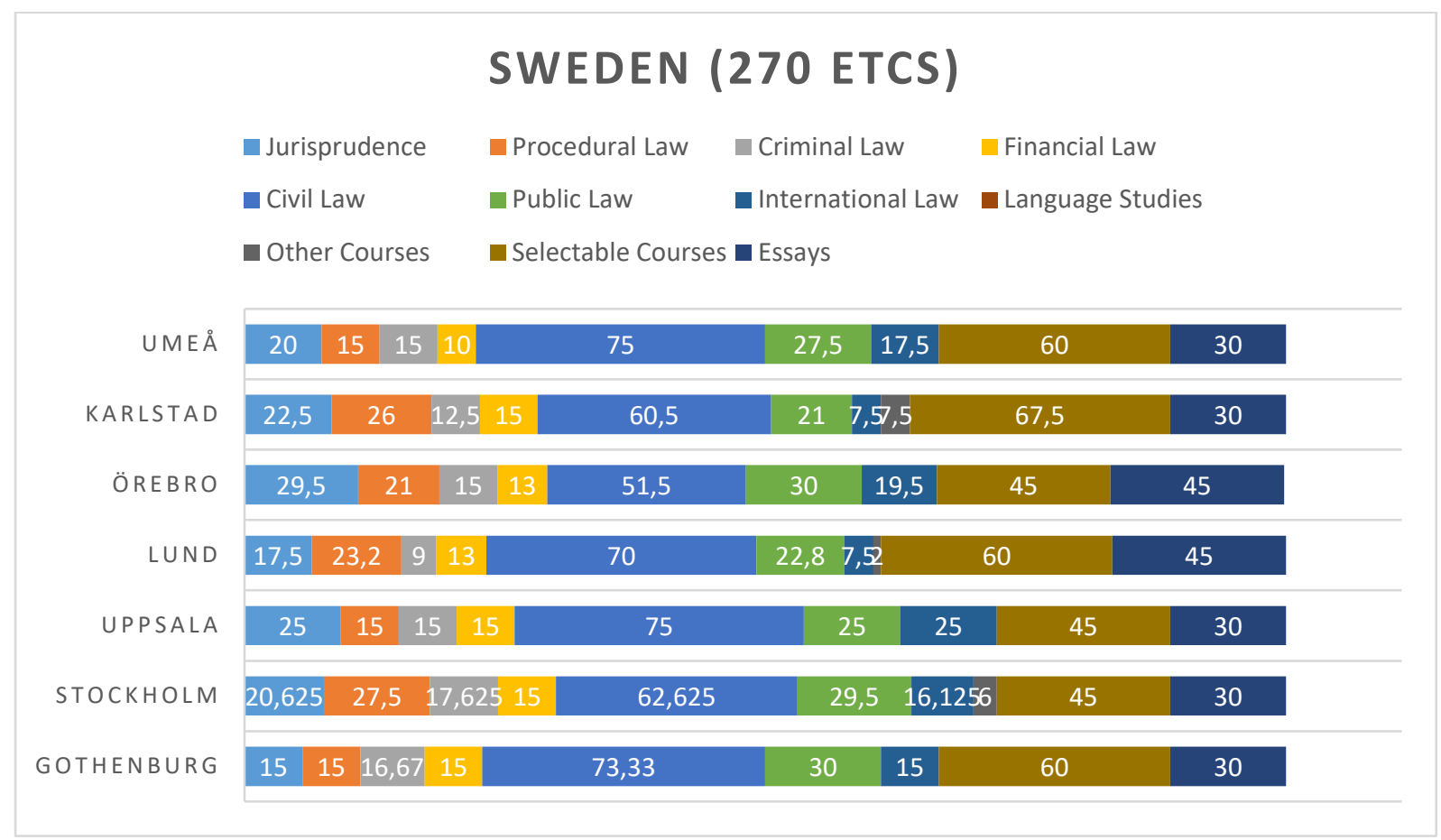

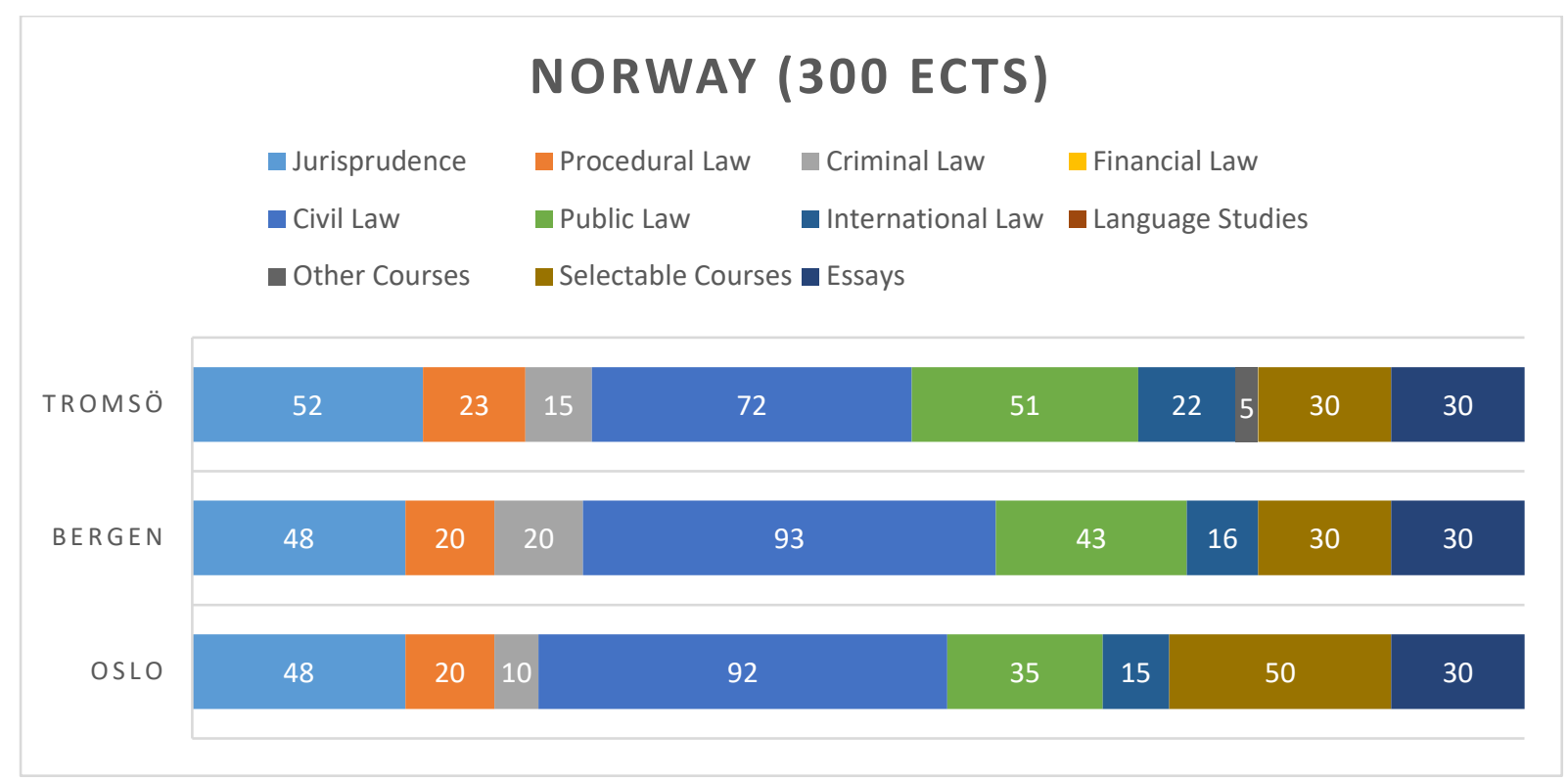




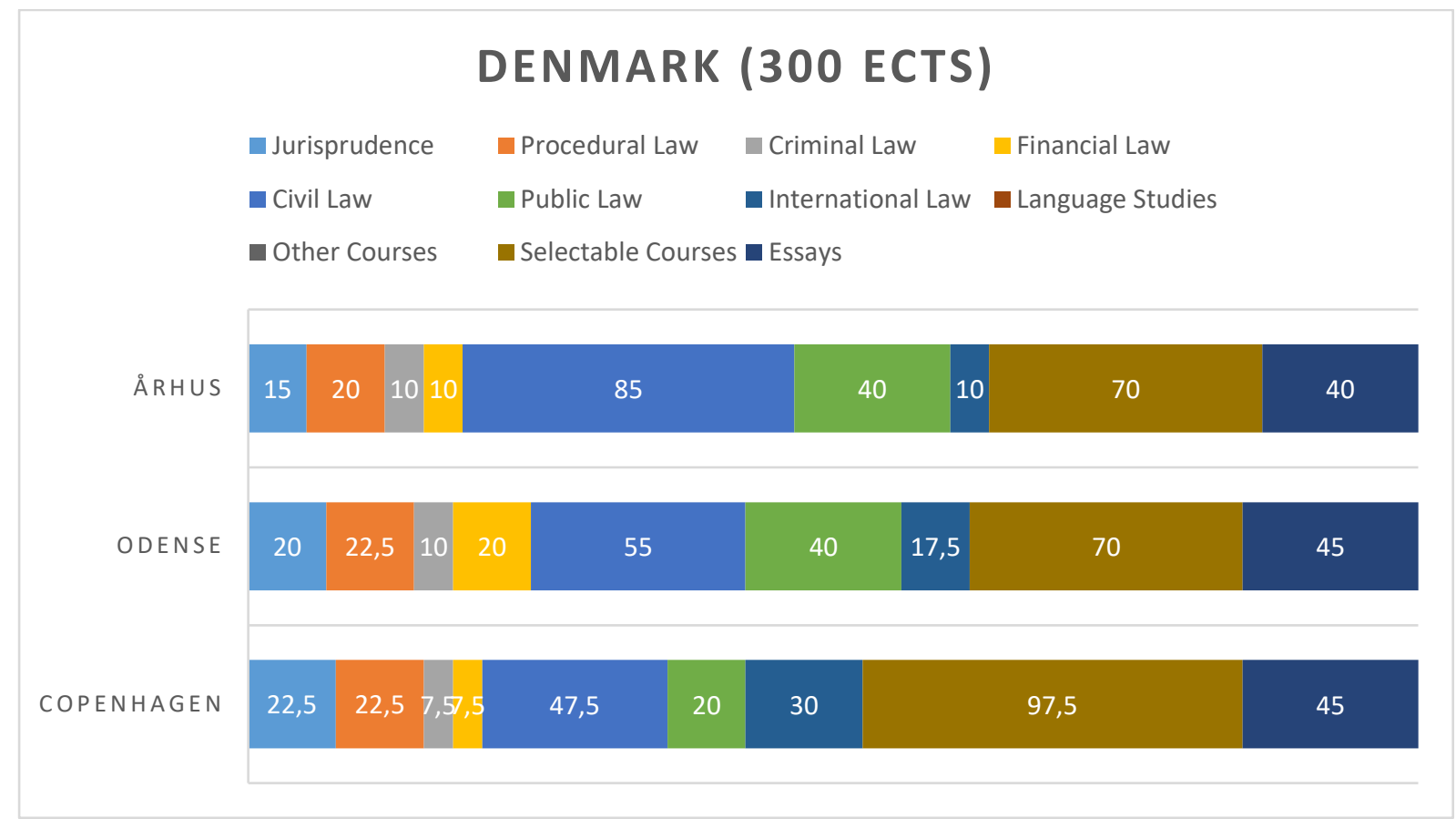

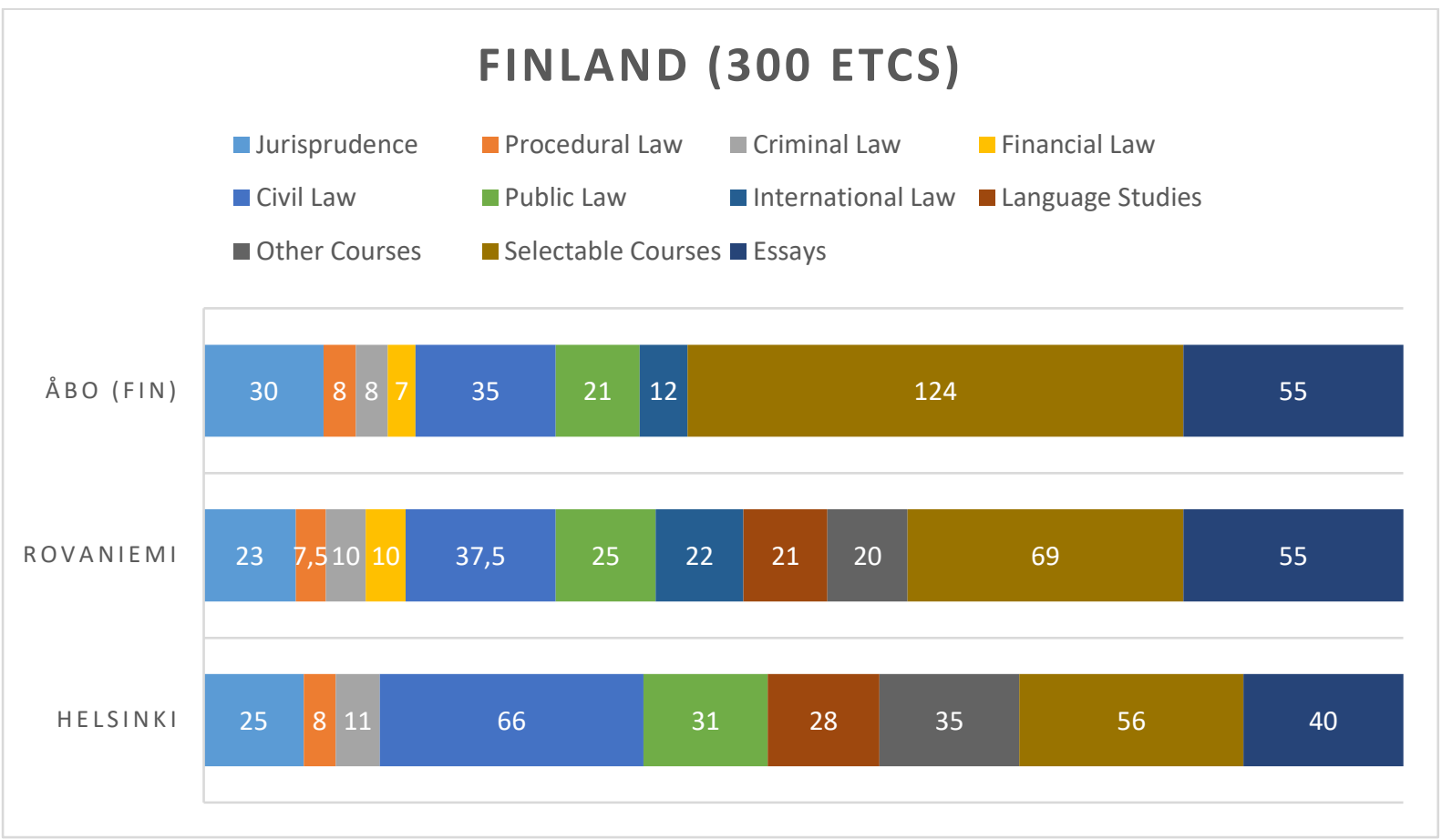




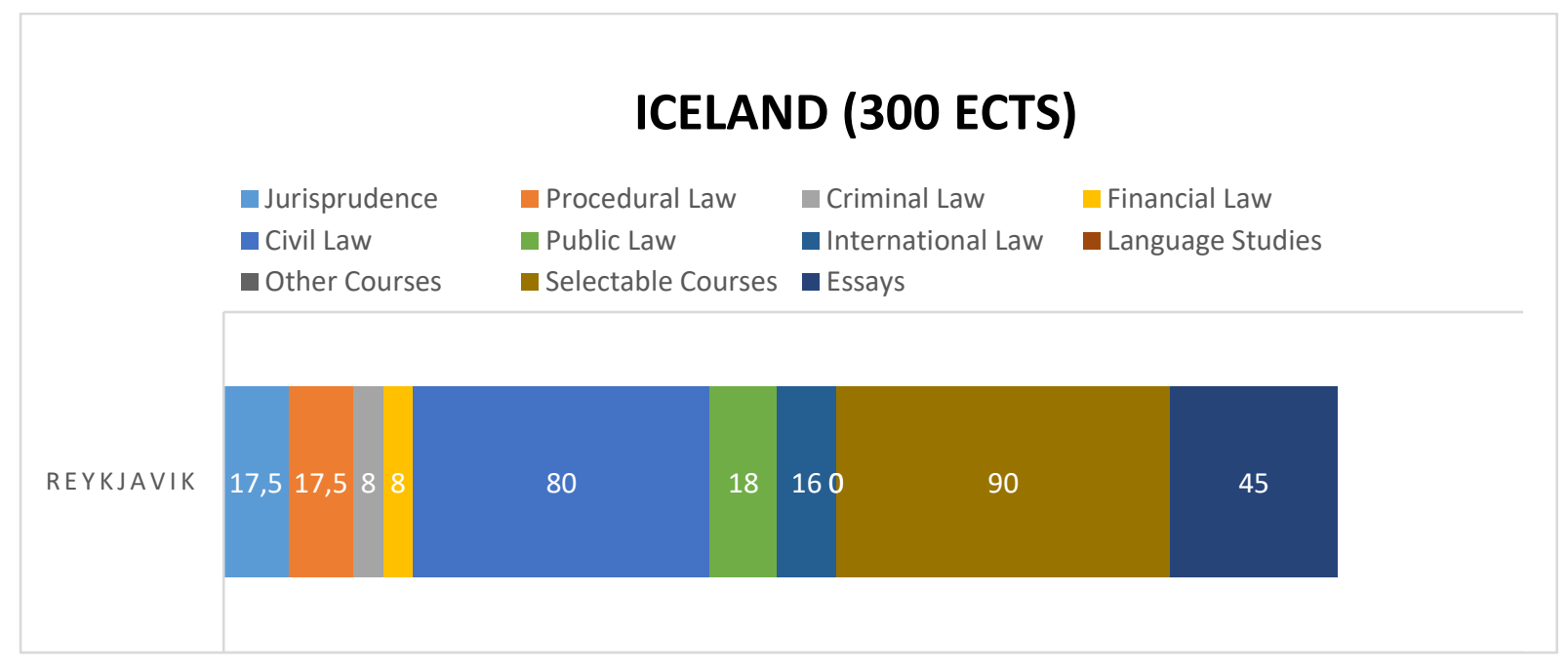

\section{Explanation of legal disciplines}

Jurisprudence:

Legal Theory, Philosophy of Law, History of Law, Sociology of Law, Comparative Law, Legal Methodology, Examen Philosophicum, Examen Facultatum, Ethics, Law and Economics, Sources of Law and Methodology, Rights Moral and Politics, Foundations of Legal Thinking, Law and Society, Legal Cultures, Criminology.

Procedural Law:

Criminal Procedure, Civil Procedure; International Private Law, Administrative Procedural Law, Conflict Resolution, Judicial Procedure.

Criminal Law:

Criminal Law.

Financial Law:

Financial Law, Tax Law, Accounting, Economics.

Civil Law:

Civil Law, Introduction to Law, Commercial Law, Law of Associations, Labor Law, Tort Law, Family Law, Intellectual Property Law, Contract Law, 
Law of Obligations, Law of Property, Competition Law, Marketing Law, Insolvency Law, Insurance Law, Lien Law, Company Law.

\section{Public Law:}

Constitutional Law, Social Law, Environmental Law, Natural Resource Law, Migration Law, Public Law, Social Family Law, Welfare Law, General Administrative Law, Special Administrative Law.

International Law:

International Law, European Union Law, European Economic Area Law, International Trade Law, International Criminal Law, International Human Rights Law, Current Issues in International Law.

\section{Course groups}

Language Studies:

General Language and Communication Studies, Linguistics, Communications.

Other Courses:

Legal Informatics, Project Seminar, Internship, Basics of Scientific Writing, Topical Theme in Law.

Selectable Courses:

Legal and non-legal topics.

Essays:

Bachelor of Laws, Master of Laws.

\section{Notes on contributor}

Miran Kakaee graduated from the LLM programme at the University of Gothenburg in the autumn of 2019. Miran has worked at Fridh Advokatbyrå since 2017 and since graduation has been active within the asylum movement and on issues related to police and the right to demonstrate. 
Nordic Journal on Law and Society

Today he also works with movement law and is the co-president of Akademin för Rörelsejurister [the academy for movement lawyers]. 